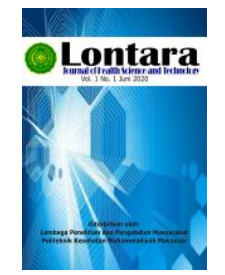

Lontara

Journal of Health Science and Technology

http://jurnal.poltekkesmu.online/lontarariset

Vol 1, No. 2, December 2020, pp 108-116

p-ISSN:0000-0000 dan e-ISSN: 2721-6179

DOI:https://doi.org/

\title{
Hubungan Indeks Massa Tubuh Terhadap Dosis Radiasi Pada Angiografi Koroner
}

\author{
Sumarsono, Indah Musdalifah \\ Radiologi, Politeknik Kesehatan Muhammadiyah Makassar \\ Email: sumarsono@poltekkesmu.ac.id
}

\begin{tabular}{l}
\hline \multicolumn{1}{c}{ Artikel info } \\
\hline Artikel history: \\
Received;03-10-2020 \\
Revised:20-11-2020 \\
Accepted;07-12-2020
\end{tabular}

Keyword:

Coronary angiography;

Radiation dose; Body

mass index.

Kata Kunci:

Angiografi Koroner;

Dosis Radiasi; Indeks

Massa Tubuh
Abstract. Cardiovascular disease is one of the leading causes of death in the world. Ionizing radiation-based diagnostic and therapeutic procedures are increasingly being used in daily clinical practice, especially in cardiology during coronary angiography. The health risks of radiation are well known. Obesity has now become an epidemic. To investigate whether the patient's Body Mass Index (BMI) has an effect on the radiation dose received by the patient during diagnostic coronary angiography. This study was an analytical observational study with a cross sectional study design to analyze the dose parameters of 48 patients who underwent coronary angiography procedures in the cardiac catheterization laboratory. Patient clinical radiation dose data in the form of kerma-area-product (DAP) and air-kerma at the intervention reference point $(\mathrm{Ka}, \mathrm{r})$ with information on the patient's height and weight to calculate the body mass index value. The data obtained were analyzed using Pearson Correlation. The statistical test conducted shows that the value of BMI against DAP and KERMA has a P-value of 0.003 and 0.006 , respectively. Because $P$-value is less than $\alpha=0.01$, there is a significant linear relationship between BMI and DAP values as well as BMI and KERMA. Obese patients require higher radiation doses than those with a normal BMI. Thus it can be used as a reference for increasing the radiation dose when performing the procedure in patients with increased BMI.

Abstrak. Penyakit kardiovaskular merupakan salah satu penyebab kematian utama di dunia. Prosedur diagnostik dan terapeutik berbasis radiasi pengion semakin banyak digunakan dalam praktik klinis sehari-hari, terutama dalam kardiologi diantaranya adalah angiografi koroner. Risiko kesehatan dari radiasi sudah diketahui dengan baik. Obesitas kini sudah mewabah.Untuk mengetahui apakah Indeks Massa Tubuh (IMT) pasien berpengaruh pada dosis radiasi yang diterima oleh pasien selama angiografi koroner diagnostik. Penelitian ini merupakan penelitian observasional analitik dengan desain penelitian cross sectional untuk menganalisis parameter dosis dari 48 pasien yang menjalani prosedur angiografi koroner di laboratorium kateterisasi jantung. Data dosis radiasi klinis 
pasien berupa kerma-area-product (DAP) dan air-kerma pada titik acuan intervensi $(\mathrm{Ka}, \mathrm{r})$ dengan informasi tinggi dan berat badan pasien untuk menghitung nilai indeks massa tubuh. Data yang diperoleh kemudian dianalisis menggunakan uji korelasi pearson. Uji statistik yang dilakukan menunjukkan bahwa untuk nilai IMT terhadap DAP dan KERMA memiliiki P-value masing-masing adalah 0.003 dan 0.006 . Karena P-value lebih kecil dari $\alpha=0.01$ maka terdapat hubungan linear yang bermakna antara IMT dan nilai DAP serta IMT dan KERMA. Pasien obesitas membutuhkan dosis radiasi yang lebih tinggi dibandingkan dengan mereka yang memiliki IMT normal. Dengan demikian dapat dijadikan acuan bahwa diperlukan peningkatan dosis radiasi saat melakukan prosedur pada pasien dengan peningkatan IMT.

Coresponden author:

Email: sumarsono@poltekkesmu.ac.id

artikel dengan akses terbuka dibawah lisensi CC BY -4.0

\section{PENDAHULUAN}

Penyakit kardiovaskular (CVD) adalah penyebab kematian nomor 1 di dunia, merenggut sekitar 17,9 juta jiwa setiap tahun. CVD adalah sekelompok kelainan jantung dan pembuluh darah dan termasuk penyakit jantung koroner, penyakit serebrovaskular, penyakit jantung rematik, dan kondisi lainnya. Empat dari 5 kematian akibat CVD disebabkan oleh serangan jantung dan stroke, dan sepertiga dari kematian ini terjadi secara prematur pada orang di bawah usia 70 tahun (Chambers, 2011).

Tindakan Diagnostik dan terapeutik berbasis radiasi pengion prosedur semakin banyak digunakan dalam praktik klinis sehari-hari, terutama dalam kardiologi seperti angiografi koroner, prosedur intervensi dan studi elektrofisiologi. (Kim et.al., 2013). Prosedur kateterisasi jantung meliputi angiografi koroner terus memberikan manfaat yang luar biasa bagi layanan kesehatan modern dan manfaat yang diperoleh pasien harus jauh lebih besar daripada risiko yang terkait dengan prosedur yang dioptimalkan dengan benar. Prosedur ini memerlukan panduan gambar fluoroskopik untuk memasang kateter di dalam jantung atau pembuluh koroner dan menyuntikkan bahan kontras radioopak untuk menemukan adanya area penyempitan maupun penyumbatan pembuluh darah koroner (Madder et.al., 2019). Pada angiografi koroner, perekaman anatomi koroner mencakup pola distribusi arteri, anatomi atau patologi fungsional (aterosklerosis, trombosis, diseksi, myocardial bridging, anomali kongenital, atau spasme koroner fokal), serta adanya hubungan kolateral antara arteri koroner dengan arteri koroner yang lain atau antar segmen pada arteri koroner yang sama. Disamping itu, angiografi koroner juga dapat menetapkan atau menyingkirkan adanya stenosis 
koroner, penentuan pemilihan terapi serta prognosis. Angiografi koroner merupakan standar penilaian gangguan anatomi koroner dan juga dipakai untuk follow up prosedur invasif atau terapi farmakologik (Osei et.al., 2019).

Selama dekade terakhir, telah terjadi peningkatan jumlah prosedur kardiologi intervensi yang dilakukan karena meningkatnya penyakit jantung dan angka kematiannya, sebagai akibatnya, ahli jantung intervensi maupun pasien berpotensi menerima dosis radiasi tinggi dalam pemeriksaan intervensi jantung. Sumber medis merupakan penyebab terbesar kedua dari paparan radiasi pada seseorang selain radiasi latar (Shah, 2015).

Angka kegemukan dan obesitas terus meningkat pada orang dewasa dan anak-anak. Dari tahun 1975 hingga 2016, prevalensi anak-anak dan remaja yang kelebihan berat badan atau obesitas berusia 5-19 tahun meningkat lebih dari empat kali lipat dari 4\% menjadi 18\% secara global. Kegemukan dan obesitas didefinisikan sebagai penumpukan lemak yang tidak normal atau berlebihan yang menimbulkan risiko bagi kesehatan. Klasifikasi Indeks massa tubuh (IMT) menurut WHO adalah berat badan kurang jika IMT $<18.5$, berat badan normal jika IMT 18.5-22.9, kelebihan berat badan IMT 23-24.9, Obesitas 1 IMT 25- 29.9 dan Obesitas 2 jika IMT lebih dari 308. Sedangkan klasifikasi IMT nasional berdasarkan Kementerian Kesehatan RI adalah kurus jika IMT <17- 18.4, normal jika IMT 18.5-25 dan Gemuk jika IMT >25. Indeks Massa Tubuh (IMT) merupakan alat yang sederhana untuk memantau status gizi orang dewasa khususnya yang berkaitan dengan kekurangan dan kelebihan berat badan. Penggunaan IMT hanya berlaku untuk orang dewasa berumur diatas 18 tahun. IMT tidak dapat diterapkan pada bayi, anak, remaja, ibu hamil dan olahragawan (WHO, 2019).

Untuk memperkirakan dosis pasien dengan benar, tipe tubuh pasien yang menjalani pemeriksaan radiografi harus dipertimbangkan. Banyak peneliti telah mempelajari dosis radiasi diserap oleh pasien selama pemeriksaan radiografi dan tipe tubuh mereka. Dalam penelitian sebelumnya, telah terbukti dosis radiasi yang efektif dari pemeriksaan sinar-X meningkat seiring dengan peningkatan ketebalan pasien untuk menjaga kualitas gambar (Wangko, dkk, 2012).

\section{METODE}

Penelitian ini merupakan penelitian observasional analitik dengan desain penelitian cross sectional untuk menganalisis parameter dosis dari 48 pasien yang menjalani prosedur angiografi koroner di laboratorium kateterisasi jantung. Metrik radiasi yang direkam untuk setiap kasus termasuk waktu fluoroskopi, kerma udara, dan produk area dosis (DAP), secara otomatis dihitung dan ditampilkan oleh sistem pencitraan fluoroskopi. Informasi tinggi dan berat badan pasien digunakan untuk menghitung nilai indeks massa tubuh. Selanjutnya Pasien dikelompokkan berdasarkan nilai IMT dengan mengacu pada klasifikasi menurut WHO. Data yang diperoleh kemudian dianalisis menggunakan Korelasi Pearson dengan software SPSS $25^{\mathrm{TM}}$. Dalam penelitian ini data dari pasien yang dianalisis berturut-turut yang menjalani prosedur angiografi koroner pada posisi frontal 
(anteroposterior) dengan durasi fluoroskopi sekitar 1 menit, untuk menghindari bias hasil yang diakibatkan oleh kompleksitas dan lamanya prosedur yang sangat bervariasi antara pasien.

\section{HASIL DAN PEMBAHASAN}

\section{A. Hasil Penelitian}

Terdapat 36 laki-laki $(75 \%)$ dan 12 perempuan $(25 \%)$ yang tercatat dalam penelitian ini dengan rentang usia 41 tahun hingga 75 tahun dengan usia rata-rata 55.8 tahun.

Grafik 1. Frekuensi jenis kelamin sampel

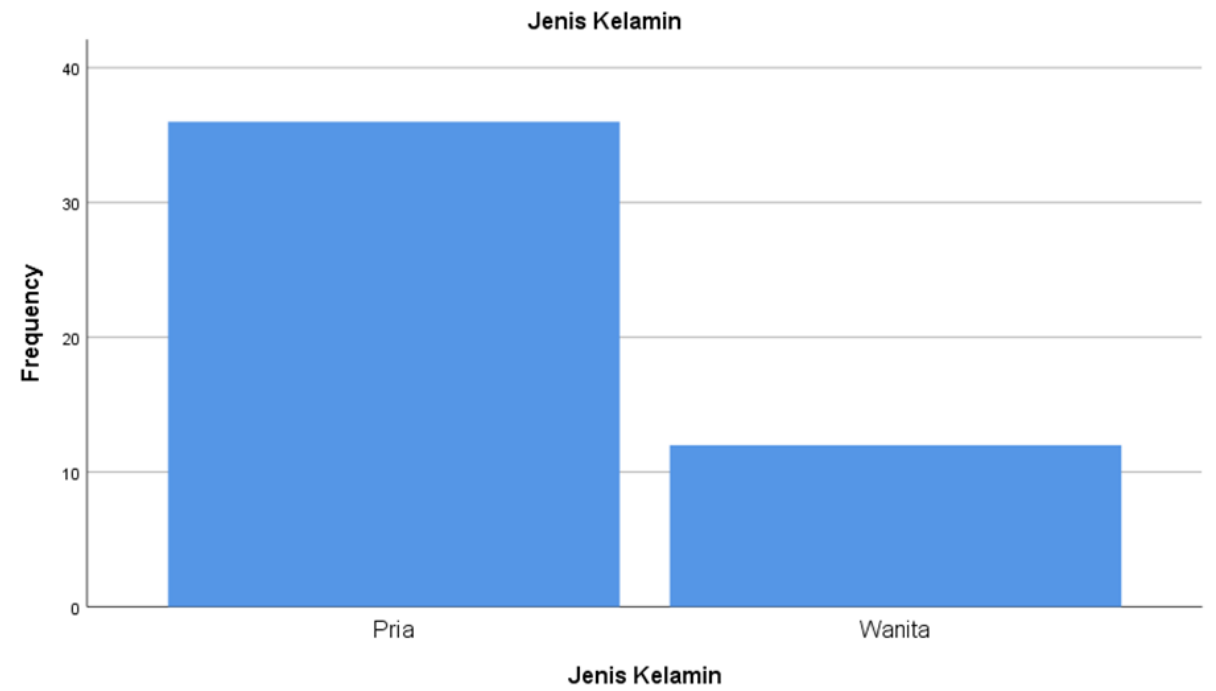

Pada Penelitian ini didapatkan pada Indeks massa tubuh yang normal berjumlah 7 orang, kelebihan berat badan 8 orang, obesitas 1 berjumlah 24 orang dan obesitas 2 berjumlah 9 orang.

Grafik 2. Frekuensi indeks massa tubuh sampel

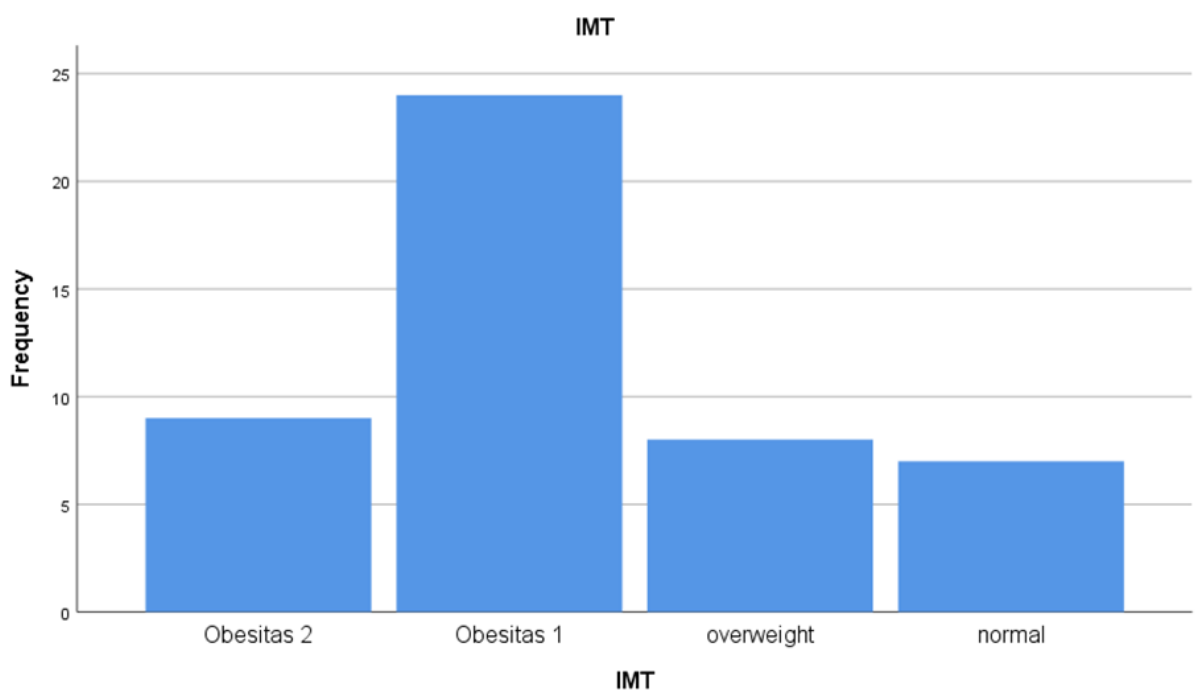


Sebaran dosis radiasi yang diperoleh adalah pada Indeks massa tubuh tipe obesitas 2 nilai KERMA rata-rata adalah $58.34 \mathrm{mGy}$ berada dalam kisaran $19.62 \mathrm{mGy}-181.13$ mGy dengan standar deviasi $\pm 54.85 \mathrm{mGy}$ dan untuk nilai DAP rata-rata $4.49 \mathrm{Gycm}^{2}$ dalam rentang $1.82{\mathrm{~Gy} . \mathrm{cm}^{2}-11.06}^{2}$ $\mathrm{Gycm}^{2}$ dengan standar deviasi $\pm 3.49 \mathrm{~Gy} . \mathrm{cm}^{2}$, Indeks massa tubuh tipe obesitas 1 nilai KERMA ratarata adalah $39.55 \mathrm{mGy}$ berada dalam kisaran $9.79 \mathrm{mGy}-111.85 \mathrm{mGy}$ dengan standar deviasi \pm 22.85 mGy dan untuk nilai DAP rata-rata $2.9 \mathrm{Gycm}^{2}$ dalam rentang $0.92 \mathrm{~Gy} . \mathrm{cm}^{2}-6.47 \mathrm{~Gy} . \mathrm{cm}^{2}$ dengan standar deviasi \pm 1.6 Gy.cm² , Indeks massa tubuh tipe kelebihan berat badan nilai KERMA rata-rata adalah 23.73 mGy berada dalam kisaran 14.16 mGy-34.82 mGy dengan standar deviasi \pm 7.48 mGy dan untuk nilai DAP rata-rata 1.96 Gy. $\mathrm{cm}^{2}$ dalam rentang 0.87 Gy. $\mathrm{cm}^{2}-3.06 \mathrm{~Gy} . \mathrm{cm}^{2}$ dengan standar deviasi $\pm 0.73 \mathrm{~Gy} \cdot \mathrm{cm}^{2}$, Indeks massa tubuh tipe normal nilai KERMA rata-rata adalah $20.68 \mathrm{mGy}$ berada dalam kisaran 10.19 mGy -34.05 mGy dengan standar deviasi \pm 8.38 mGy dan untuk nilai DAP rata-rata 1.69 Gy. $\mathrm{cm}^{2}$ dalam rentang $1.04 \mathrm{~Gy} . \mathrm{cm}^{2}-2.37 \mathrm{~Gy} . \mathrm{cm}^{2}$ dengan standar deviasi \pm 0.45 Gy.cm²,

Tabel 1. Uji Korelasi Pearson IMT terhadap DAP dan KERMA

\begin{tabular}{llrrrr}
\hline & & IMT & DAP & \multicolumn{1}{c}{ KERMA } \\
\hline \multirow{2}{*}{ IMT } & Pearson Correlation & 1 & $-.425^{* *}$ & $-.395^{* *}$ \\
\cline { 2 - 5 } & Sig. (2-tailed) & & .003 & .006 \\
\cline { 2 - 6 } & $\mathrm{N}$ & $-.425^{* * *}$ & 48 & 48 \\
\hline \multirow{2}{*}{ DAP } & Pearson Correlation & .003 & 1 & $.927^{* *}$ \\
\cline { 2 - 5 } & Sig. (2-tailed) & 48 & 48 & .000 \\
\cline { 2 - 5 } & $\mathrm{N}$ & $-.395^{* *}$ & $.927^{* *}$ & 48 \\
\hline \multirow{2}{*}{ KERMA } & Pearson Correlation & .006 & .000 & 1 \\
\cline { 2 - 5 } & Sig. (2-tailed) & 48 & 48 & 48 \\
\cline { 2 - 5 } & $\mathrm{N}$ & & & \\
\hline
\end{tabular}

**. Correlation is significant at the 0.01 level (2-tailed).

Uji statistik yang dilakukan menunjukkan bahwa untuk nilai IMT terhadap DAP dan KERMA memiliiki P-value masing-masing adalah 0.003 dan 0.006 . Karena P-vaue lebih kecil dari $\alpha=0.01$ maka terdapat hubungan linear yang bermakna antara IMT dan nilai DAP serta IMT dan KERMA.

\section{B. Pembahasan}

Tren ke arah prosedur invasif minimal dalam beberapa dekade terakhir telah menghasilkan pertumbuhan eksponensial dalam prosedur kardiologi berbasis kateter yang dipandu fluoroskopi. Karena teknik ini menjadi lebih umum digunakan dan dikembangkan, efek merugikan dari paparan radiasi pada pasien, operator, dan staf tambahan telah menjadi perhatian. Meskipun batas dosis radiasi pekerjaan sedang dipantau dan jarang tercapai, paparan terhadap radiasi dosis rendah kronis telah terbukti memiliki efek biologis berbahaya yang tidak langsung terlihat sampai bertahun-tahun kemudian.

Paparan radiasi di lingkup pelayanan kesehatan merupakan perhatian utama bagi pekerja laboratorium kateterisasi jantung. Radiasi tidak memiliki ambang batas keamanan minimum dan efek sampingnya terjadi dalam risiko linier yang bergantung pada dosis (WHO, 2017). Efek berbahaya 
radiasi pengion pada jaringan manusia telah diketahui sebagai deterministik atau stokastik. Cedera radiasi deterministik mengacu pada kematian sel ketika paparan melebihi ambang tertentu. Efek stokastik mengacu pada cedera yang terjadi sebanding dengan dosis radiasi kumulatif dari waktu ke waktu.

Tabung sinar-x fluoroskopi bekerja memproduksi sinar-x untuk tujuan pencitraan organ anatomi yang berpotensi untuk bergerak (organ movement) secara real-time. Pada tindakan intervensional, fluoroskopi digunakan untuk memantau pergerakan dan posisi kateter yang masuk pada pembuluh darah menuju lokasi pengamatan secara langsung (real time). Pada pesawat angiografi modern, dosis KERMA maupun Dose Area Product (DAP) selama pemeriksaan ditampilkan pada panel kendali. Dua indikator utama tersebut merupakan besaran dosimetrik terukur yang dapat digunakan untuk memperkirakan risiko radiasi. Gy. $\mathrm{cm}^{2}$ digunakan untuk memperkirakan risiko stokastik pada pasien sedangkan mGy berkaitan dengan reaksi jaringan.

Beberapa hal yang mempengaruhi dosis radiasi pada pasien dan personil pelaksana tindakan dengan mode fluoroskopi antara lain (1) Tegangan tabung $(\mathrm{kVp})$ menentukan daya tembus dari sinar$\mathrm{X}$ pada pesawat angiografi tegangan tabung meningkat untuk pasien yang lebih gemuk, (2) kuat arus tabung (mA) adalah jumlah dari emisi radiasi per satuan waktu. Peningkatan dari produksi arus seimbang dengan peningkatan radiasi yang keluar, paparan pasien, dan brightness citra. Jika kualitas citra pada monitor TV kurang bagus untuk pasien yang kurus, ini dapat diperbaiki dengan meningkatkan $\mathrm{mA}$. Untuk pasien yang lebih kurus lebih disukai dengan peningkatan $\mathrm{kVp}$, akibatnya akan meningkatkan radiasi yang keluar sehingga membutuhkan pengurangan $\mathrm{mA}$. Untuk pasien yang sangat kurus maka membutuhkan pengaturan peningkatan $\mathrm{kVp}$ dan $\mathrm{mA}$, (3) waktu penyinaran pada tindakan angiografi koroner biasanya lebih panjang dibandingkan dengan radiografi lain sehingga paparan radiasi dapat dikurangi dengan mengupayakan tindakan yang singkat yang dilakukan oleh operator terlatih, (4) Jarak Penyinaran; semakin dekat pasien dengan tabung sinar-x maka dosis yang diterima akan semakin besar mengupayakan posisi yang sedekat mungkin dengan penguat citra yang memberikan keuntungan pada pengurangan dosis masuk kulit untuk pasien, dan magnifikasi dan distorsi geometri rendah, (5) Kolimasi berkas sinar-X: pengurangan dosis yang besar dari pasien dan pekerja dapat dicapai dengan menggunakan kolimator untuk mengatur ukuran berkas sinar-X.

Dalam literatur dan berbagai metode telah digunakan untuk merekam dosis radiasi yang telah terpajan pada pasien. Dua yang paling umum adalah DAP dan dosis efektif. DAP adalah metode sederhana, mudah diukur dan merupakan jumlah total radiasi yang dipancarkan oleh peralatan sinar-x. Pengukur DAP adalah bagian integral dari tabung sinar-X dan keluarannya diukur mG.m² atau G.cm². Dose area product (DAP) merupakan indikator risiko radiasi yang bagus untuk pasien, karena tidak hanya mengetahui besarnya dosis serap yang diterima pasien selama pemeriksaan namun juga menunjukkan luasan daerah yang teriradiasi. Data DAP diakumulasi selama fluoroskopi dan fluorografi (sine). Nilai yang tercatat menunjukkan batas maksimum dosis yang diserap oleh pasien 
tanpa adanya transmisi dan hamburan. Dari nilai DAP yang diperoleh, untuk menghitung dosis efektif yang diterima oleh pasien. Metode lain untuk mengukur paparan dosis radiasi adalah menghitung dosis efektif dengan menggunakan rumus yang membutuhkan faktor koefisien yang didasarkan pada variasi radiosensitifitas berbagai jaringan sehingga tidak populer digunakan.

Total kerma udara (AK) pada titik referensi intervensi (juga disebut Ka,r, Gy) adalah AK kumulatif. AK adalah energi sinar-x yang dikirim ke udara pada titik referensi intervensi. Ini adalah nilai pemantauan radiasi yang diperlukan pada sistem sinar X intervensi sejak 2006. Ka,r digunakan untuk memantau dosis pasien karena dikaitkan dengan efek deterministik pada kulit. Efek deterministik adalah dosis radiasi yang menghasilkan efek kesehatan langsung. Pengalaman dan penelitian telah menetapkan nilai ambang batas untuk berbagai efek. AK, bagaimanapun, bukanlah dosis puncak kulit yang sebenarnya. Dosis pada kulit pasien dapat diestimasi dari KERMA (kinetic energy released per unit mass) udara di titik referensi (Ka,r) sebagai kuantitas dosimetrik.

Cumulative kerma dose atau juga biasa disebut dose entrance merupakan jumlah akumulasi dosis karena mode fluoroskopi dan mode sine fluorografi. Cumulative kerma dose yang merupakan kerma udara yang diukur pada jarak $15 \mathrm{~cm}$ dari isosenter ke arah fokus. Titik itulah yang dalam IEC standard 60601-2-43 disebut sebagai IRP (interventional reference point) yang dinyatakan dalam unit Gy.. Perkiraan dosis pasien dapat diketahui dengan menghitung PSD (Peak Skin Dose) dari cumulative dose tersebut. cara yang paling mudah adalah dengan inverse square law.

Pengamatan utama dari penelitian ini, yang mengevaluasi hubungan antara IMT pasien dan dosis radiasi pada tindakan angiografi koroner, adalah bahwa peningkatan IMT pasien dikaitkan dengan peningkatan dosis radiasi. Pengamatan ini konsisten dengan konsep bahwa dosis radiasi pasien yang lebih tinggi, yang juga diamati meningkat secara bertahap dengan IMT pasien, dan akan menghasilkan jumlah radiasi hamburan yang lebih tinggi, yang menjadi sumber utama paparan radiasi pada dokter yang melakukan kateterisasi jantung.

Peningkatan obesitas ini kemungkinan berdampak pada penggunaan radiasi di laboratorium kateterisasi karena pasien obesitas yang menjalani prosedur fluoroskopi menerima dosis radiasi yang lebih besar daripada pasien non obesitas. Peningkatan dosis radiasi ini disebabkan oleh peningkatan energi yang diperlukan untuk mengatasi atenuasi jaringan dan memfasilitasi jumlah foton yang cukup untuk mencapai penguat gambar untuk menghasilkan gambar yang memadai (Bluemke, et.al., 2008).

Konsisten dengan penelitian lainnya yang menunjukkan prevalensi obesitas yang tinggi di antara pasien yang menjalani kateterisasi jantung. Terdapat $>50 \%$ dari populasi penelitian mengalami obesitas, dan $18 \%$ dari populasi penelitian mengalami obesitas yang tidak sehat. Mendukung konsep bahwa peningkatan prevalensi obesitas dapat memberikan dampak negatif pada keselamatan radiasi pasien, penelitian ini menunjukkan peningkatan yang signifikan pada dosis radiasi pasien di seluruh kategori IMT yang meningkat. Mempertimbangkan peningkatan risiko kesehatan yang dihadapi oleh petugas dikombinasikan dengan prevalensi obesitas yang meningkat di laboratorium kateterisasi, maka hasil penelitian ini mungkin memerlukan tindak lanjut terhadap penerapan praktik keselamatan radiasi 
yang lebih agresif di era epidemi obesitas. Petugas harus menyadari tentang kemungkinan tingkat paparan radiasi yang lebih tinggi dari pasien obesitas dan menerapkan strategi perlindungan tambahan untuk mengurangi paparan.

Untuk itu penerapan proteksi radiasi dengan pengurangan paparan dosis radiasi di laboratorium kateterisasi jantung harus menjadi prioritas meliputi pendidikan dan pelatihan staf, pemantauan dosis radiasi, memastikan penggunaan peralatan pelindung diri yang tepat, penggunaan pelindung, dan berbagai teknik prosedural dalam meminimalkan radiasi memerlukan perhatian yang serius.

\section{KESIMPULAN}

Pasien obesitas membutuhkan dosis radiasi yang lebih tinggi dibandingkan dengan mereka yang memiliki BMI normal. Dengan demikian dapat dijadikan acuan bahwa terjadi peningkatan dosis radiasi saat melakukan prosedur pada pasien dengan peningkatan IMT.

\section{UCAPAN TERIMA KASIH}

Terima kasih diucapkan kepada Direktur, dan seluruh civitas akademika prodi Radiologi Politeknik Kesehatan Muhammadiyah Makassar yang telah membantu terlaksananya seluruh rangkaian penelitian ini.

\section{DAFTAR PUSTAKA}

Bluemke, D. A., Achenbach, S., Budoff, M., Gerber, T. C., Gersh, B., Hillis, L. D., ... \& Woodard, P. K. (2008). Noninvasive coronary artery imaging: magnetic resonance angiography and multidetector computed tomography angiography: a scientific statement from the American Heart Association Committee on Cardiovascular Imaging and Intervention of the Council on Cardiovascular Radiology and Intervention, and the Councils on Clinical Cardiology and Cardiovascular Disease in the Young. Circulation, 118(5), 586-606.

E. Chambers, C., A. Fetterly, K., Holzer, R., Paul Lin, P. J., C. Blankenship, J., Balter, S., \& K. Laskey, W. (2011). Radiation safety program for the cardiac catheterization laboratory. Catheterization and Cardiovascular Interventions, 77(4), 546-556.

ICRP. 2007 Recommendations of the International Commission on Radiological Protection. (2007). ICRP publication 103. Ann ICRP, 37(2-4), 1-332.

Kim, H., Park, M., Park, S., Jeong, H., Kim, J., \& Kim, Y. (2013). Estimation of absorbed organ doses and effective dose based on body mass index in digital radiography. Radiation protection dosimetry, 153(1), 92-99.

Madder, R. D., VanOosterhout, S., Mulder, A., Ten Brock, T., Clarey, A. T., Parker, J. L., \& Jacoby, M. E. (2019). Patient Body Mass Index and Physician Radiation Dose During Coronary Angiography: Is the Obesity Epidemic Impacting the Occupational Risk of Physicians in the Catheterization Laboratory?. Circulation: Cardiovascular Interventions, 12(1), e006823. 
Osei, B., Xu, L., Johnston, A., Darko, S., Darko, J., \& Osei, E. (2019). Retrospective study of patients radiation dose during cardiac catheterization procedures. The British Journal of Radiology, 92(1099), 20181021.

Shah, A., Das, P., Subkovas, E., Buch, A. N., Rees, M., \& Bellamy, C. (2015). Radiation dose during coronary angiogram: relation to body mass index. Heart, Lung and Circulation, 24(1), 21-25.

Shabani, F., Hasanzadeh, H., Emadi, A., Mirmohammadkhani, M., Bitarafan-Rajabi, A., Abedelahi, A., ... \& Sanchooli, M. (2018). Radiation protection knowledge, attitude, and practice (KAP) in interventional radiology. Oman medical journal, 33(2), 141.

Supariasa, I. D. N., Bakri, B., \& Fajar, I. (2001). Penilaian Status Gizi. Jakarta. Penerbit buku kedokteran EGC.

Wangko, L. C., Budiono, B., \& Lefrandt, R. L. (2012). ANGIOGRAFI KORONER INDIKASI, KONTRAINDIKASI, DAN PROTEKSI TERHADAP RADIASI. JURNAL BIOMEDIK: JBM, 4(3).

Webb, W. R., \& Higgins, C. B. (2010). Thoracic imaging: pulmonary and cardiovascular radiology. Lippincott Williams \& Wilkins.

WHO. Cardiovascular Disesae. (2017).

World Health Organization. (2019). Obesity and Overweight: World Health Organization.(2018). 